\title{
ГРАММАТИКА МЕДИАРЕЧИ
}

\author{
УДК $81 ’ 42$
}

\section{Автономия пользователей Сети и динамика грамматики: о выбранных синтаксических инновациях в современной польской интернет-коммуникации}

\author{
Э. Шкудлярек-Щмехович \\ Лодзинский университет, \\ Польша, 90-236, Лодзь, ул. Поморска, 171/173
}

Для цитирования: Шкудлярек-Щмехович, Э. (2021). Автономия пользователей Сети и динамика грамматики: о выбранных синтаксических инновациях в современной польской интернет-коммуникации. Медиалингвистика, 8 (1), 57-70. https://doi.org/10.21638/spbu22.2021.105

Использование языка в интернете представляет собой наиболее важную среду для формирования новых языковых обычаев и вариативных форм. Представлены результаты поиска и количественного и качественного анализа двух синтаксических конструкций odnośnie do kogo, czego и dedykowany komu, сzети - и их ненормативных узуальных вариантов: ${ }^{\star}$ odnośnie kogo czego; ${ }^{*}$ dedykowany, ${ }^{*}$ dedykowany dla kogo, czego; ${ }^{*}$ dedykowany do $k o g o$ czego. Обе проанализированные конструкции и их узуальные варианты - это аналитические выражения, заменяющие более простые синтаксические структуры (здесь: co do, jeśli chodzi o или do/dla) и негативно оцениваемые лингвистами, занимающимися языковой нормой. В исследовании учитывается как числовое соотношение нормативных и ненормативных конструкций, так и сравнительные данные, полученные из различных типов дискурсов и медиатекстов, в том числе из польской интернет-речи в ее интерактивном и неинтерактивном вариантах. Кроме того, в исследовании сравниваются данные разных периода (до 2000 г., 2001-2010 гг.), когда польский язык не подвергался (или подвергался, но в меньшей степени) влиянию сетевого общения. Источниками данных послужили Национальный корпус польского языка, поисковая система интернетсообщений Monco PL, а также сервис интернет-форумов Forumowisko PL. Главная цель исследования - предварительная реализация исследовательских постулатов как в области нормативной лингвистики (разработка инструментов, которые позволят заново кодифицировать эталонную норму польского языка), так и в области медиалингвистики (разработка критериев оценки, правил общения в Сети, которые будут учитывать нормативный аспект в сочетании с правилами, управляющими коммуникацией в интернете).

Ключевые слова: интернет-коммуникация, языковая норма, динамика языка, синтаксические инновации, изменчивость синтаксиса.

(C) Санкт-Петербургский государственный университет, 2021 
Введение. Среди многих медиалингвистических вопросов, в частности о том, «в какой степени медиа моделируют коммуникативное поведение, как и с помощью каких вербальных средств они влияют на концептуализацию действительности в обществе» [Skowronek 2013: 251], есть также вопросы о том, «что медиа “делают” с языком, в какой степени моделируют грамматическую систему» [Skowronek 2013: 251]. Кажется, что «достаточно произвольно выбрать какой-то элемент подсистемы языка, чтобы иметь возможность доказать факт воздействия на него определенных медиа» [Skowronek 2013: 250], однако постоянно исследователи обращают внимание на один и тот же (достаточно очевидный) реестр системных фактов, а особенно внесистемных, которые подвергаются воздействию новых медиа: пунктуация, орфография, проникновение синтаксических особенностей разговорного языка в письменную речь, стремительное обогащение словарного состава языка. Сложнее определить конкретные изменения, которые происходят в языке под влиянием постоянных социокультурно-коммуникативных преобразований, с которыми мы сталкиваемся на протяжении двух десятилетий. Если изменения лексического характера четко и хорошо описаны в лингвистической литературе, то изменения грамматики подвергаются анализу намного реже, поскольку происходят не так быстро и не с такой легкостью, с какой меняется словарный запас, что влечет за собой сдвиги на уровне словообразовательной подсистемы (см.: [Jadacka 2001; Kleszczowa 2012, Waszakowa 2017]).

Представленные далее результаты исследования, полученные на основе корпусных данных, касаются количественного и качественного анализа двух синтаксических конструкций и их узуальных вариантов. Мы учитывали как числовое соотношение нормативных и ненормативных конструкций, так и сравнительные данные, полученные из различных типов дискурсов и медиатекстов, в том числе из польской интернет-речи в ее интерактивном и неинтерактивном варианте. Данные, демонстрирующие использование языка в интернете, представляют собой наиболее важную среду для формирования новых языковых явлений [Kita 2016a: 120] и вариативных форм, что в дальнейшем может повлечь за собой изменение языковой нормы.

Научные контексты. Изучение динамики синтаксических явлений находится в пределах лингвистических субдисциплин: описательной грамматики, нормативной лингвистики, культуры языка и корпусной лингвистики. Важным ориентиром становится медиаконтекст, поскольку динамика грамматики определяется прежде всего особенностями интернет-дискурса и его участников.

К основным характеристикам онлайн-медиатекстов исследователи новых медиа чаще всего относят интерактивность, гипертекстуальность, мультимедийность и мультимодальность (полисемиотичность, поликодовость) (см.: [Grzenia 2006; Żydek-Bednarczuk 2013; Jarosz, Opiłowski, Staniewski 2015; Kita 2016b; Maćkiewicz 2016; Pędzisz 2017]). Однако с точки зрения проведенных исследований важными являются свойства интернет-общения, характеризующие участников и отчасти обусловленные интерактивностью: индивидуализм и субъектность, находящие выражение в самостоятельности, независимости и коммуникативном творчестве отправителей, свободе в выражении взглядов, выборе темы, стиля, жанра и языковых средств, а также спонтанности, не существовавшей до сих пор нигде, кроме живой речи. Спонтанное интернет-сообщение фиксируется, сохраняется, публикуется, но «без необходимости запуска соответствующих процедур, связанных с изданием текстов» [Grzenia 2006: 105]. Письменная речь (в традиционной версии - печат- 
ной форме) объединяет нормы, придает им межрегиональный диапазон, вводит кодификацию, тормозящую бурное развитие системы [Wilkoń 2000: 36]. Между тем спонтанные, но сохраненные интернет-тексты характеризуют, с одной стороны, стихию разговорного языка и нестабильность нормы, с другой - своего рода фиксацию этого нестабильного состояния.

В польской нормативной традиции до 1990-х гг. существовало понятие языковой нормы, которая не подлежала диверсификации: выражение, форма выражения, синтаксическая конструкция признавались нормативными или ненормативными, соответствовали норме или нет (см., например: [Buttler, Kurkowska, Satkiewicz 1986]). После 1989 г., когда с развитием медиа произошла экспансия разговорного языка, укрепилась концепция двухуровневой нормы: образцовой (эталонной) и утилитарной (разговорной) [Markowski 1999; 2005a; 2005b]. Анджей Марковский признал допустимость в польском языке форм, низших, чем эталонные, вредной для культуры языка и общественной коммуникации: «Развитие общественного польского языка идет по направлению к отклонению его от канонов эталонной нормы, и это должно настораживать. Думаю, что следует четко подчеркнуть тот факт, что определенные коммуникативные ситуации и определенные виды речи требуют использования в них исключительно утвержденных в эталонной норме языковых средств. Создание области хорошего польского языка, а значит, польского, основанного на эталонной норме, позволит сохранить нашему языку идентичность в процессе глобализации и обеспечить ему непрерывность развития, связь с прошлыми эпохами. Отдельный, но очень важный вопрос - новая кодификация эталонной нормы польского языка. Необходимо выработать такие инструменты, которые позволят объективно установить принадлежность отдельных слов, их форм, связей и значений к уровню эталонной нормы» [Markowski 2007].

Изменения в медиасфере за последние два десятилетия, связанные с развитием СМИ и социальных сетей, блогосферы, технологических возможностей публиковать письменные комментарии практически под любым интернет-сообщением, не облегчают задачу ни лингвистам, занимающимся языковой нормой, ни медиалингвистам. Культура участия [Jenkins 2006] и связанная с ней нейтрализация оппозиции между производителем и потребителем (см.: [Toffler 1985; Wolny 2013; Baruk 2017]), производителем и пользователем (англ. user), а в коммуникационном пространстве - между отправителем и получателем [Kita 2016b] несет в себе существенные изменения в социокультурном ранге пассивных получателей. Активные пользователи новых медиа - «продюсеры» и «просьюмеры» - не до конца понимают важность роли, которую они играют в новой дигитализированной коммуникативной реальности, т. е. в процессе опосредованного межсубъектного общения, которое происходит в основном в публичном пространстве. В конце концов «основным измерением медиа является трансляция ценностей, которая всегда осуществляется в перспективе определенных, сознательных или бессознательных обязанностей и целей. Медиа уже навсегда вписаны в logos и ethos человеческой жизни, поэтому они также являются пространством ценностей» [Drożdż 2009: 72]. В таком отношении автономия активных участников сетевого общения подразумевает не только возможность выбора, но и ответственность за содержание и форму сообщения как средства социокультурного воздействия и как элемента, конституирующего современную культуру, включая язык и его динамику. 
Поэтому при попытках сегодня понять проблему языковой нормы невозможно не обратить внимание на то, что активные пользователи интернета делают с языком. Появляются концепции нормативного инварианта, рядом с которым функционирует множество коммуникативных норм различных групп, и в каждой из них «не столько действуют другие нормы, сколько существует другой способ восприятия морального обязательства по отношению к членам группы, результатом чего является другой диапазон критериев оценок поведения, в том числе речевого (например, в определенных группах, сосредоточенных в интернете, автономной ценностью становится развлекательность речевого поведения, а такой критерий, как совместимость единицы с системой, вообще отсутствует). Аксиологии неоплемен (сообществ, созданных в интернете ${ }^{1}$. - Э. Ш.-Щ.) отличаются от системы ценностей общества как такового» [Kłosińska 2017: 85].

Понятие нормативного инварианта сочетает в себе оригинальную концепцию недиверсицированной нормы (в понимании А. Марковского - нормы образцовой) с узуальным «состоянием хаоса», который отражает общение в Сети и в котором следовало бы рассматривать наиболее выразительные (сохраненные, задокументированные) проявления динамики языка, которая, в свою очередь, относится как к изменениям, наблюдаемым в определенный момент времени, так и к вариативности языковых явлений [Dolník 2010: 67; Kleszczowa 2012].

Несмотря на то что динамика языка и ее результаты чаще всего рассматриваются в аспекте развития языка, это не означает, что нельзя изучать их синхронически. Результат и прямое выражение динамики языка в синхроническом выражении - актуальная вариативность языковых явлений [Sojda 2016: 166]. Однако в диахроническом и синхроническом аспектах разные возможности описания языка: «Когда в историко-лингвистических исследованиях речь идет о лингвистических изменениях, мы обычно фокусируем внимание на ходе выбранного процесса, стремясь добраться до его истоков. А что касается конца, а значит, эффекта от процесса, то он у нас уже есть. Такой взгляд на современный нам язык невозможен. Можно говорить о начале, можно показать ход, хотя бы в перспективе десятилетий, а то и нескольких лет, но каков будет эффект того, что сейчас происходит, мы не знаем. Мы можем в лучшем случае прогнозировать, предвидеть, однако гипотезы проверить невозможно» [Kleszczowa 2012: 173].

Основной причиной языковых изменений считается чрезмерная размытость правила языка, которая не приводит к появлению «сил, упорядочивающих состо-

${ }^{1}$ Ср.: «Современные сообщества, которые создаются в интернете, имеют характер неоплемен [Maffesoli 2008] (собственно веб-племен [Pigla 2012]), главная цель которых - быть “вместе без цели" [Maffesoli 2008: 126]. Они реализуют эмоциональные и аксиологические потребности индивидов и создают собственные нормы - последнее необходимо для регулирования функционирования групп и прежде всего их автономизации. Языки неоплемен можно было бы считать социолектами, если бы не два серьезных препятствия. Во-первых, социолекты - это языки сред, сосредоточенных вокруг какой-то идеи, занятия или общего опыта, а неоплемена - это... группы, созданные для того, чтобы быть “вместе без цели”. Во-вторых, что для наших соображений о языковой норме намного важнее - ...это языки, существующие в публичном пространстве, но созданные группами. Отношение общих лингвистических образцов к языковому поведению членов этих групп кажется бессмысленным, поскольку это поведение санкционировано только группой, а иногда противоречит общим нормам. В таком плане следовало бы говорить не об отсутствии стабильности одной нормы, а о существовании множества различных норм, функционирующих рядом с общей нормой, на которую они влияют» [Kłosińska 2017: 85]. 
яние хаоса», в то время как косвенным свидетельством нарушения правила являются ошибки и сомнения в выборе языковых средств [Kleszszczowa 2012: 174]. Языковая система, однако, обладает способностью приспосабливаться: она изменяется, но в то же время поддерживает состояние равновесия, не допускает столько вариантов, которые могли бы ослабить ее функциональность [Sojda 2016: 158]. К основным общим механизмам, динамизирующим язык и имеющим формальную, функциональную или формально-функциональную природу, относятся: а) субстанция, т. е. механизм замены первичных форм эквивалентными новыми или существующими в системе формами или механизм изменения функции языкового средства при сохранении его формы и расширении значения; б) мультипликация, т. е. увеличение формальных и функциональных элементов в языке; в) редукция, т. е. уменьшение или утрата языковых элементов, их функции или формы без замены другими [Sojda 2016: 159-160; Kralčák 2010: 460-462].

Описание процедуры исследования. Для первичного анализа были выбраны две лексемы, синтаксические требования которых (однозначно определенные языковой нормой) характеризуются узуальной вариативностью, выходящей за норму: odnośnie do czego / *odnośnie czego ${ }^{2}$ (в отношении чего); dedykowany komu, czemu / *dedykowany I *dedykowany dla kogo, czego / *dedykowany do czego (посвященный кому, чему). Воспроизведение в соответствии с правилами польского языка синтаксических схем, в центре которых находятся главные слова, по мнению Ханны Ядацкой [Jadacka 2005: 150], одна из самых сложных нормативных проблем. Синтаксические конструкции такого типа требуют от пользователей запоминания правил синтаксической связности, что связано с трудностями правильного усвоения, а затем воспроизведения таких словосочетаний [Jadacka 2005: 156]. Пользователи языка должны решить вопросы, касающиеся, во-первых, выбора типа соединения: синтетическое соединение и морфологическая аккомодация (например, *odnośnie kogo, czego; dedykowany komu, czemu) [Grzegorczykowa 1998: 66], во-вторых - подбора определенного зависимого слова или определенного предлога, например do или dla.

Наше исследование, проведенное на фоне нормативных рекомендаций, направлено на сравнение синтаксических вариантов, появляющихся в онлайн-текстах (интерактивных и неинтерактивных), с вариантами, выбранными в других типах сообщений (здесь: печатные книжные сообщения). Наиболее существенной величиной, которая послужит для заключительных выводов, является количественное соотношение вариативных конструкций в специально подобранных для исследования корпусах текстов. Помимо взаимного, горизонтального сопоставления данных, важны также вертикальные, хронологические различия. Временны́ми рамками исследования стали 2000 г. (быстрое развитие новых медиа) и 2010 г. (предельная дата данных, содержащихся в Национальном корпусе польского языка - далее НКПЯ).

Для исследования были использованы онлайн-тексты, содержащиеся:

а) в Национальном корпусе польского языка ${ }^{3}$, с разделением на интерактивные интернет-тексты (форумы, чаты, списки обсуждений и т.д.) и неинтерактивные онлайн-тексты (веб-сайты);

\footnotetext{
${ }^{2}$ Неправильные конструкции помечены знаком [*].

${ }^{3}$ Общее число слов составляет 1,5 млрд сегментов [Przepiórkowski i in. 2012].
} 
б) корпусе актуальных интернет-текстов Monco PL ${ }^{4}$;

в) корпусе интернет-форумов Forumowisko $\mathrm{PL}^{5}$.

В качестве референтных корпусов выбраны НКПЯ, стилистически сбалансированный НКПЯ и книги, включенные в НКПЯ. Наиболее важным сравнением, благодаря которому можно понять динамику грамматики, считаем не только временны́е отношения, но и сравнение данных, извлеченных из интернет-корпусов, с данными из «книжного» канала в НКПЯ.

Выбор диагностических примеров в значительной степени произвольный, хотя каждый из наборов вариативных конструкций представляет свой механизм, динамизирующий язык: от простой формальной субституции odnośnie do czego / *odnośnie czego через формально-семантическую субституцию dedykowany komu/ czemu / dedykowany к распространению ненормативных конструкций: dedykowany komu/czemu (в значении 'предназначенный для чего-то, кого-то') / *dedykowany dla kogo/czego / *dedykowany do czego, а иногда даже *dedykowany pod kogo, czego / *dedykowany od kogo, czego / *dedykowany na kogo, czego. Обе конструкции отражают предпочтения отправителей письменных сетевых текстов: пользователи интернета выбирают описательные, аналитические конструкции, а не простые, соответствующие устной речи.

Количественные корпусные данные представлены в таблицах 1 и 2, которые позволят сравнить вариативность языковых явлений как во времени, так и в определенном типе текстов или дискурсов. Однако изучение вариативных конструкций не ограничивалось только сбором статистических данных, автоматически генерируемых поисковыми системами. Не раз приходилось просматривать все результаты поиска, чтобы выделить только те, которые удовлетворяют существенным семантико-контекстным условиям. В случае семантического анализа, если примеров было до 1000, прослеживались все контексты, если больше - количество анализируемых использований ограничивалось 1000. Описание современных языковокоммуникативных явлений не может основываться только на количественных данных, следует также учитывать социальные, институциональные или медиаусловия [Galiński, Liberek, Wierzchoń 2018].

\section{Анализ примеров и характеристика результатов поиска}

\section{1) odnośnie do czego / *odnośnie czego}

Выражение odnośnie do - «1) касается (кого/чего); 2) что касается» [Żmigrodz$\mathrm{ki}$, sine data]. В первом значении конструкция представляет собой стилистически окрашенный (относящийся к официальной разновидности языка) показатель связи, во втором значении - показатель отношения. Квазисинонимами в первом значении являются выражения á propos, ad, co do, w odniesieniu do, w stosunku do, во втором значении - á propos, co do, co się tyczy, jeśli chodzi o, jeśli idzie o [Żmigrodzki, sine data]. Значения выражения и его синтаксическая структура служат аналогами глаголов odnosić do 'признавать что-то, о чем идет речь; касается человека, явления

\footnotetext{
${ }^{4}$ Monco PL - поисковая система, которая содержит интернет-тексты. Индекс поисковика включает около 5 млрд слов и постоянно актуализируется [Pęzik 2019; 2020].

${ }^{5}$ Forumowisko PL [forumowisko.pl] - один из множества интернет-сервисов со встроенной поисковой системой, который объединяет около 60 форумов в рамках 13 тематических блоков.
} 
или ситуации, названной существительным, входящим в состав следующего предложного выражения' и odnosić się do 'иметь отношения с кем-то или чем-то, о ком или о чем говорится’ [Żmigrodzki, sine data]; cp.: odnosić do, odnosić się do, odniesienie do, odnośnie do. Обе конструкции - odnośnie do // *odnośnie kogo, czego — используются особенно часто в интернет-коммуникации как показатель отсылки: в комментариях, на форумах, в ответах на сообщения других пользователей Сети, требующих ссылаться на их высказывания и указание expressis verbis межтекстовых связей. Метатекстовый характер выражения отражает основную особенность общения в Сети - гипертекстуальность, которая на самом деле не имеет здесь формы ссылок или тегов, но является простой, вербальной, не нуждающейся в информационно-технологических способностях ссылкой на другой текст.

Последний польский орфоэпический словарь рекомендует как исключительную, единственно правильную конструкцию odnośnie do, cp.: «odnośnie офиц. 'относительно кого-то, чего-то; по делу кого-то, чего-то; в отношении кого-то, чего-то'. Odnośnie do kogoś, do czegoś (не: kogoś, czegoś): Uwagi odnośnie do ostatniego punktu (не: odnośnie ostatniego punktu; лучше: co do ostatniego punktu) ${ }^{6}$ » [Markowski 2005a]. Более либеральный в нормативном отношении Słownik wyrazów kłopotliwych ${ }^{7}$ [Bańko, Krajewska 1995] признает конструкцию odnośnie kogoś, czegoś приемлемой в официальном общении ${ }^{8}$ : «Конструкция odnośnie kogoś, czegoś имеет официальный характер. В изданиях по грамматике эта конструкция считается излишним русицизмом, который можно заменить выражениями odnośnie do czegoś, w odniesieniu do czegoś, $w$ stosunku do czegoś, wobec czegoś или менее официальными w sprawie czegoś і co do czegoś. Иногда, впрочем, критикуемое выражение вообще можно пропустить» [Bańsko, Krajewska 1995: 217-218].

Вопрос о выражении odnośnie (do) czego три раза обсуждался в Центре лингвистического консультирования PWN, что означает, что, во-первых, пользователи часто спрашивают про эту конструкцию (кстати, нормативную конструкцию признают часто неправильной) [Rosińska-Mamej 2018: 213]), во-вторых, сами лингвисты признают ее трудной, ср.: «О выражении odnośnie czegoś можно сказать, что оно соответствует общепринятой норме, но не соответствует норме установленной. Лучшее, что может сделать словарь в такой ситуации, это сообщить о столкновении норм. От словарей правильного польского языка поляки ожидают, однако, чтобы они были немного консервативны, так что понятие многопунктной нормы (как мы предлагаем назвать освещение в словаре разных точек зрения) долго может быть непринятым. И поэтому новый “Словарь правильного польского языка" более эластичен, чем его предшественники, поскольку он релятивизирует нормативные оценки коммуникативной ситуации, предъявляя, например, меньше требований к разговорной беседе, чем к официальной переписке» [Bańko 2009].

Развитие новых медиа, распространенность сетевых коммуникаций, многое изменили в использовании и маркировании конструкции, признанной в образцовой норме некорректной (табл. 1). Выражение, согласующееся с установленной нормой (odnośnie do), имеет преимущество перед ненормативной конструкцией

\footnotetext{
6 «Замечания относительно последнего пункта».

7 «Словарь трудных слов».

${ }^{8}$ Необходимо обратить внимание на дату выхода словаря: 1995 г. Таким образом, не возникает вопроса о влиянии польского интернета на изменчивость конструкции в то время.
} 
Таблица 1. Корпусные данные, касающиеся конструкций odnośnie do czego / *odnośnie czego

\begin{tabular}{|c|c|c|c|}
\hline \multirow[b]{2}{*}{ Тип корпуса } & \multicolumn{3}{|c|}{ Числовые данные, касающиеся конструкции } \\
\hline & $\begin{array}{l}\text { odnośnie } \\
\text { do czego }\end{array}$ & $\begin{array}{l}\text { *odnośnie } \\
\text { czego }\end{array}$ & $\begin{array}{c}\text { числовое соотношение } \\
\text { odnośnie do czego / ^odnośnie czego }\end{array}$ \\
\hline \multicolumn{4}{|c|}{ Референтные корпусы } \\
\hline НКПЯ целый & 9826 & 23463 & $1: 2$ \\
\hline до 2000 г. & 5010 & 2060 & $2,5: 1$ \\
\hline 2001-2010 гг. & 4378 & 21065 & $1: 5$ \\
\hline НКПЯ сбалансированный & 2145 & 2399 & $1: 1$ \\
\hline до 2000 г. & 973 & 324 & $3: 1$ \\
\hline 2001-2010 гг. & 980 & 2002 & $1: 2$ \\
\hline НКПЯ — «книжный» канал & 649 & 468 & $1,5: 1$ \\
\hline до 2000 г. & 129 & 190 & $1: 1,5$ \\
\hline 2001-2010 гг. & 520 & 276 & $2: 1$ \\
\hline \multicolumn{4}{|c|}{ Профилированные (интернет-) корпусы } \\
\hline НКПЯ - интернет-канал & 560 & 15147 & $1: 30$ \\
\hline Неинтерактивный & 89 & 3043 & $1: 34$ \\
\hline Интерактивный & 463 & 11905 & $1: 26$ \\
\hline Monco & 19651 & 126430 & $1: 6$ \\
\hline Forum & 0 & 200 & $0: 200$ \\
\hline
\end{tabular}

Ис т очн и к: составлена автором.

(odnośnie kogo, czego) в трех референтных корпусах. Стоит подчеркнуть, что аналитическая конструкция более распространена, чем синтетическая, в основном в подкорпусах текстов до 2000 г. Существуют также количественные различия во временной структуре по всему корпусу (выражение odnośnie do превосходит выражение *odnośnie kogo, czego в два с половиной раза в текстах до 2000 г., а выражение *odnośnie kogo, czego - в текстах 2001-2010 гг. в пять раз). Соответствующие онлайн-корпусы не оставляют сомнений относительно того, какое выражение доминирует в польском языке. Нельзя не заметить, что именно интернет-коммуникация является основным местом популяризации синтетической формы (ср. полное отсутствие нормативной структуры в корпусе, представляющем дискуссионные форумы). В интернет-коммуникации это чрезвычайно популярная конструкция почти 65 \% выражений во всем НКПЯ происходит из подкорпуса интернет-текстов.

Трудно предсказать, как будет развиваться языковая судьба выражения odnośnie kogo, czego, но очень вероятно, что синтетическая конструкция вытеснит существующую аналитическую нормативную конструкцию odnośnie do, несмо- 
тря на опору в составе глагола, от которого она происходит (odnosić do, odnosić się do). В пользу этого свидетельствует как количество употреблений синтетических структур, особенно в сетевом общении, так и постоянное увеличение важности интернет-общения и его влияния на динамику языка. Популярность конструкции в Сети, несмотря на ее первоначальное официальное назначение, сочетается с интерактивностью и гипертекстуальностью сетевых сообщений. С одной стороны, пользователи упрощают структуру, с другой - охотно используют ее, хотя чаще всего она бывает излишней и может быть заменена простым выражением со do или свойственным живому общению jeśli chodzi o. Интернет-пользователи выбирают официальный и немного искусственный вариант.

\section{2) dedykowany komu/czemu / *dedykowany dla kogo/czego / *dedykowany do czego}

Форма dedykowany - это страдательное причастие, созданное от переходного глагола dedykować 'символически жертвовать кому-то свое творение или достижение как выражение любви, уважения или благодарности' [Żmigrodzki, sine data] и входящее в состав трех обязательных аргументных выражений: ktoś dedykuje coś komuś, czemuś, в пассивном использовании - coś jest dedykowane komuś, czemuś przez kogoś. Под влиянием значений английского глагола dedicate и адъективной формы dedicated (только перед существительным) ' 1 . believing that an activity or idea is important and giving a lot of energy and time to it; 2 . used only for one particular purpose or job' [Cambridge Dictionary, sine data] в польском языке среди пользователей, связанных с новыми технологиями, произошло расширение значения слова. Dedykować используется уже не только в значении 'предложить кому-то свое творение или достижение', но и в значении 'пожертвовать, посвятить', a dedykowany - это 'тот, который имеет конкретное предназначение, разработан или используется для одной конкретной цели'. Изменение смысла повлекло за собой изменение синтаксического уровня.

Синтетическая конструкция без предлогов, которая возникает гораздо чаще, чем предложные конструкции (табл. 2), имеет три варианта: dedykowany komu cze$m u$ - нормативный вариант с использованием аргумента в дательном падеже (например, prace dedykowane ojcu), *dedykowany komu czemu в значении 'предназначен для чего-то или для кого-то' - вариант не соответствует образцовой норме с семантической точки зрения (например, program komputerowy dedykowany użytkownikom urzadzeń mobilnych ${ }^{9}$ ); ${ }^{*}$ dedykowany - формально и семантически ненормативный вариант в функции безаргументного определения существительного (напримep, ${ }^{*}$ dedykowany serwer ${ }^{10}$ ).

Использование в качестве прилагательного без аргумента характеризуется препозицией в отношении определяемого существительного или именной фразы, так же как англ. dedicated, например dedykowana łączność, dedykowana sieć bezprzewodowa, dedykowana linia komunikacyjna, dedykowana lampa, dedykowana soczewka, dedykowana ładowarka, dedykowana platforma trackingowa, dedykowana drukarka ${ }^{11}$. На весь НКПЯ приходится один случай такого употребления лексемы dedykowany

\footnotetext{
9 «Компьютерная программа посвящена пользователям мобильных устройств».

10 «Выделенный сервер».

11 «Специальная связь», «выделенная беспроводная сеть», «выделенная линия связи», «специальная лампа», «специальная линза», «выделенное зарядное устройство», «специальная платформа отслеживания», «выделенный принтер».
} 
Таблица 2. Корпусные данные, касающиеся конструкций dedykowany koтu, сzemu / dedykowany dla kogo, czego / dedykowany do kogo, czego

\begin{tabular}{|c|c|c|c|c|}
\hline \multirow[b]{2}{*}{ Тип корпуса } & \multicolumn{4}{|c|}{ Числовые данные, касающиеся конструкции } \\
\hline & $\begin{array}{l}\text { dedykowany } \\
\text { komu, } \\
\text { czemu }\end{array}$ & $\begin{array}{c}{ }^{*} \text { dedykowany } \\
\text { dla kogo, } \\
\text { czego }\end{array}$ & $\begin{array}{c}\text { *dedykowany } \\
\text { do kogo, } \\
\text { czego }\end{array}$ & $\begin{array}{c}\text { числовое соотношение } \\
\text { dedykowany dla: } \\
\text { dedykowany do }\end{array}$ \\
\hline \multicolumn{5}{|c|}{ Референтные корпусы } \\
\hline НКПЯ целый & 7145 & 279 & 408 & $1: 1,5$ \\
\hline до 2000 г. & & 15 & 31 & $1: 2$ \\
\hline 2001-2010 гг. & & 257 & 374 & $1: 1,5$ \\
\hline НКПЯ сбалансированный & 1285 & 103 & 39 & $2,5: 1$ \\
\hline до 2000 г. & & 5 & 6 & $1: 1$ \\
\hline 2001-2010 гг. & & 98 & 33 & $3: 1$ \\
\hline НКПЯ — «книжный» канал & 339 & 7 & 5 & $1,5: 1$ \\
\hline до 2000 г. & & 1 & 2 & $1: 2$ \\
\hline 2001-2010 гг. & & 6 & 3 & $2: 1$ \\
\hline \multicolumn{5}{|c|}{ Профилированные (интернет-) корпусы } \\
\hline НКПЯ - интернет-канал & 3692 & 216 & 376 & $1: 2$ \\
\hline неинтерактивный & 1180 & 33 & 26 & $1: 1,5$ \\
\hline интерактивный & 2507 & 124 & 334 & $1: 3$ \\
\hline Monco & 88204 & 975 & 688 & $1,5: 1$ \\
\hline Forum & 447 & 36 & 26 & $1,5: 1$ \\
\hline
\end{tabular}

Ис т о ч н и к: составлена автором.

на 100 примеров. Намного чаще встречается нормативная с формальной точки зрения (coś dedykowane czemuśs ${ }^{12}$ ), но ненормативная с точки зрения значения и семантической связности конструкция, являющаяся контаминацией выражений przeznaczony do czegoś или dla kogoś и kierowany do kogoś, например nowa wersja Google Maps for Mobile dedykowana użytkownikom urządzeń mobilnych; Cyborg - mysz dedykowana graczom; wyszukiwarka dedykowana dzieciom; drukarka laserowa A4 dedykowana małym i średnim przedsiębiorstwom; system operacyjny dedykowany netbookom; nawigacja dedykowana kierowcom; witryna internetowa dedykowana usłudze Simpuls ${ }^{13}$. Многие из этих конструкций - совершенно ненужные аналитизмы, заменяющие

\footnotetext{
12 «Что-то, посвященное чему-то».

13 «Предназначен для чего-то или для кого-то» и «направленный кому-то», например «новая версия Google Maps for Mobile предназначена для пользователей мобильных устройств»; «Суborg — мышь, предназначенная для игроков»; «поисковая система, предназначенная для детей»; «лазерный принтер A4, предназначенный для малых и средних предприятий»; «операционная система, пред-
} 
короткие, простые и, что самое главное, не вызывающие никаких нормативных сомнений словосочетания: system operacyjny do netbooków; nawigacja dla kierowców; mysz dla graczy; Google Maps dla użytkowników; wyszukiwarka dla dzieci ${ }^{14}$ и т. д. Синтаксическими вариантами ненормативного в семантическом плане выражения, в свою очередь, являются новые синтаксические соединения: ${ }^{\star}$ dedykowany dla и *dedykowa$n y d o$ в значении 'предназначенный для чего-то или для кого-то'. Оба формальносемантических варианта множат ненормативное употреблении конструкции соś dedykowane komuś, czemuś в значении 'предназначенный для чего-то или для когото'. Числовое сопоставление профилированных (интернет-) и референтных корпусов (см. табл. 2) не оставляет сомнений в том, что новые синтаксические связи характерны для интернет-коммуникации, а контексты использования указывают прежде всего на их тематическую связь с новыми технологиями. При этом стоит обратить внимание на распространенность использования ненормативных предложных конструкций на интернет-форумах. Кроме dedykowany dla / ^dedykowany do используются также (правда, редко, хотя это не единичные экземпляры) сочетания ${ }^{*}$ dedykowany pod ( ${ }^{*}$ dedykowane pod program Photoshop; ${ }^{*}$ serwery dedykowane pod gry typu Tibia), ${ }^{*}$ dedykowany od ( ${ }^{*}$ pakiety hostingu dedykowanego od Statnet.pl), ${ }^{*}$ dedykowany na (*oprogramowanie dedykowane na systemy Linux/Windows). Таким образом, мы имеем задокументированное состояние «узуального хаоса», которое сопровождается появлением новых языковых единиц.

Выводы. Представленные результаты поиска и их характеристика могут послужить основой для составления предварительных выводов об анализируемых конструкциях и связанной с ними динамике языка. Исследование также показывает определенные тенденции, с которыми мы имеем дело на уровне системы и на прагматическом уровне, в языковых привычках пользователей польского языка, в том числе пользователей Сети, и влиянии их речевого поведения на вариативность языковых явлений и языковую норму. Они также могут верифицировать описание особенностей польской интернет-речи.

Корпусные данные, отражающие охват и частоту встречаемости определенной конструкции, представляют аргументы в пользу того, что образцовая форма odnośnie do kogo, czego является сегодня (в основном под влиянием интернета) структурой рецессивной, охотно заменяемой пользователями формой ${ }^{*}$ odnośnie kogo, czego. В свою очередь, новое ненормативное с семантической точки зрения выражение *dedykowany komu, czemu в значении 'предназначен для чего-то, или для кого-то' становится конструкцией экспансивной, модной, имеющей расшатанную, неуверенную, размноженную форму: ${ }^{\star}$ dedykowany, ${ }^{\star}$ dedykowany do, ${ }^{\star}$ dedykowany pod, ${ }^{\star}$ dedykowany od, *dedykowany na.

Количественные сравнительные исследования различных типов корпусов приносят конкретные данные о влиянии интернет-коммуникации на языковые обычаи и в дальнейшем на языковую норму. Это влияние, как показывают сравнения, значительно в основном из-за документированного характера такого типа коммуникации.

\footnotetext{
назначенная для нетбуков»; «навигация, предназначенная для водителей»; «сайт предназначенный для услуги Simpuls».

14 «Операционная система для нетбуков»; «навигация для водителей»; «мышь для геймеров»; «Google Maps для пользователей»; «поисковая система для детей».
} 
Однако наиболее интересными кажутся выводы, которые можно отнести к особенностям сетевого общения. Обе проанализированные конструкции и их узуальные варианты - это аналитические выражения, заменяющие более простые синтаксические структуры (здесь: co do, jeśli chodzi o или do/dla) и как таковые негативно оцениваемые лингвистами, занимающимися языковой нормой, хотя уже для прессы 1960-х гг. показательно: «Если есть на выбор две формы: аналитическая и синтетическая, выбирается [в прессе. - Э.Ш.-Щ.] первая, а если такой не существует в языке, создается искусственная, стилистически неудобная, так как она растянутая, тяжелая и часто не выражает достаточно ясно мысль» ([Kniagininowa 1963: 149]; цит. по: [Burska 2016: 15]). Аналогично обстоит дело и в современных текстах пользователей Сети: вместо простой и правильной синтаксической структуры используются аналитические конструкции - избыточные и ненормативные, характерные для официальной разновидности языка, для газетных текстов или (более широко) для письменной речи (ср.: [Burska 2016: 15]). В использовании предложных аналитизмов, укреплении их вариативных форм, размножении аналитических форм и их существовании в интернет-коммуникации следовало бы рассматривать влияние официального польского языка на письменную интернет-речь. Несомненно, существует много особенностей разговорного языка, которые имеют свое отражение в интернет-коммуникации, однако нельзя не замечать влияния не всегда лучших образцов письменного польского языка и закрепления их в сохраненной сетевой коммуникации (см. исследование о частоте аналитических конструкций на польском телевидении, которые стоят в оппозиции к довольно распространенному мнению об экспансии разговорности в СМИ как современной доминирующей особенности: [Loewe 2010]).

Современные инструменты и методы исследований, которые предоставляет корпусная лингвистика, не только не могут быть переоценены в системных исследованиях и исследованиях дискурса, но и должны быть включены в медиалингвистические исследования. Благодаря им и специально подобранным корпусам можно определить влияние интернет-коммуникации на языковые изменения и описать реальные языковые особенности сетевого общения в его различных вариантах.

\section{Литература/References}

Bańko, M., Krajewska M. (1995). Słownik wyrazów kłopotliwych. Warszawa, Wydawnictwo Naukowe PWN.

Bańko, M. (2009). Odnośnie (do) czegoś. Retrieved from: https://sjp.pwn.pl/poradnia/haslo/odnosnie-doczegos;10350.html.

Baruk, A. I. (2017). Prosument jako aktywny uczestnik działań marketingowych. Zeszyty Naukowe Szkoły Głównej Gospodarstwa Wiejskiego Ekonomika i Organizacja Gospodarki Żywnościowej, 117, 123-136.

Burska, K. (2016). Analityzmy leksykalne i ich syntetyczne odpowiedniki w prasie. Łódź, Wydawnictwo Uniwersytetu Łódzkiego.

Buttler, D., Kurkowska, H., Satkiewicz, H. (1986). Kultura języka polskiego. Vol. 1. Warszawa, Wydawnictwo Naukowe PWN.

Cambridge Dictionary. Retrieved from: https://dictionary.cambridge.org/.

Dolník, J. (2010). Synchrónna dynamika morfológie. In J.Dolník (Ed.), Morfologické aspekty súčasnej slovenčiny (pp. 65-96). Bratislava, Veda.

Drożdż, M. (2009). Norma personalistyczna i autonomia uczestnicząca w komunikowaniu medialnym. In M. Steciąg, M. Bugajski (Eds.), Norma a komunikacja (pp. 71-83). Wrocław, Atut.

Graliński, F., Liberek, J., Wierzchoń P. (2018). Badania nad współczesnym uzusem i jego ewolucją w świetle danych gromadzonych metodami lingwistyki komputerowej. Na wybranych przykładach z zakre- 
su morfologii, składni i leksyki. In P.Zbróg (Ed.), Wybrane aspekty badań nad norma (pp. 49-85). Kraków, Wydawnictwo LIBRON.

Grzegorczykowa, R. (1998). Wykłady z polskiej składni. Warszawa, Wydawnictwo Naukowe PWN.

Grzenia, J. (2006). Komunikacja językowa w Internecie. Warszawa, Wydawnictwo Naukowe PWN.

Jarosz, J., Opiłowski, R., Staniewski, P.Ed. (2015). Lingwistyka mediów. Antologia tłumaczeń. Wrocław, Atut; Dresden, Neisse Verlag.

Jadacka, H. (2001). System słowotwórczy polszczyzny (1945-2000). Warszawa, Wydawnictwo Naukowe PWN.

Jadacka, H. (2005). Kultura języka polskiego. Fleksja, słowotwórstwo, składnia. Warszawa, Wydawnictwo Państwowe PWN.

Jenkins, H. (2006). Kultura konwergencji. Zderzenie starych i nowych mediów. Translat. Bernatowicz, M., Filiciak, M. Warszawa, Wydawnictwa Akademickie i Profesjonalne.

Kita, M. (2016a). Językoznawcy wobec badań języka w Internecie. Artes Humanae, 1, 111-124.

Kita, M. (2016b). Język w internecie. Rozpoznanie stanu wiedzy. In M. Kita, I. Loewe (Ed.), Język w internecie. Antologia (pp. 10-56). Katowice, Wydawnictwo Uniwersytetu Śląskiego.

Kleszczowa, K. (2012). Tajemnice dynamiki języka. Katowice, Wydawnictwo Uniwersytetu Śląskiego.

Kłosińska, K. (2017), Istnienie i kształt normy językowej po przełomie cyfrowym. Biuletyn Polskiego Towarzystwa Językoznawczego, 73, 49-85.

Kniagininowa, M. (1963). Struktury opisowe - znamienna cecha stylu dziennikarskiego. Język Polski, XLIII, $148-157$.

Kralčák, L. (2010). Mechanizmy dynamiky jazyka. In Šimková M. (Ed.), Slovo - tvorba - dynamickost’ (pp. 460-466). Bratislava, Veda Publ.

Maffesoli, M. (2008). Czas plemion. Schyłek indywidualizmu w społeczeństwach ponowoczesnych. Warszawa, Wydawnictwo Naukowe PWN.

Loewe, I. (2010). Konstrukcje analityczne w polskiej telewizji na progu drugiej dekady XXI wieku. Stylistyka $19,177-188$.

Maćkiewicz, J. (2016). Jak można badać przekazy multimodalne. Język Polski, XCVI (2), 18-27.

Markowski, A. (Ed.) (1999). Nowy słownik poprawnej polszczyzny. Warszawa, Wydawnictwo Naukowe PWN.

Markowski, A. (Ed.) (2005a). Wielki słownik poprawnej polszczyzny. Warszawa, Wydawnictwo Naukowe PWN.

Markowski, A. (2005b). Kultura języka polskiego. Teoria. Zagadnienia leksykalne. Warszawa, Wydawnictwo Naukowe PWN.

Markowski, A. (2007). Norma wzorcowa. Retrieved from: http://www.rjp.pan.pl/index.php?option=com_ content\&view=article\&id=1354\&Itemid=50.

Pędzisz, J. (2017). "Komentuj na blogu”: interakcje w blogosferze jako perspektywa badawcza w analizie dyskursu internetowego. Lingwistyka Stosowana, 21, 115-126.

Pęzik, P. (2019). Korpusowe narzędzia weryfikacji frazeostylistycznej tłumaczeń. Konińskie Studia Językowe, 7 (3), 317-339.

Pęzik, P. (2020). Budowa i zastosowania korpusu monitorującego MoncoPL. Forum Lingwistyczne, 7, $133-150$.

Pigla, W. (2012). Webplemię — próba eksplikacji pojęcia. Kultura i Historia, 21. Retrieved from: http://www. kulturaihistoria.umcs.lublin.pl/archives/3837.

Przepiórkowski, A., Bańko, M., Górski, R.L., Lewandowska-Tomaszczyk, B. (2012). Narodowy Korpus Jezzka Polskiego. Warszawa, Wydawnictwo Naukowe PWN.

Rosińska-Mamej, A. (2018). Czy norma wzorcowa istnieje? Opinie studentów na temat normy wysokiej oraz posługujących się nią użytkowników języka. In P.Zbróg (Ed.), Wybrane aspekty badań nad normą (pp. 211-230). Kraków, LIBRON Publ.

Skowronek, B. (2013). Mediolingwistyka. Wprowadzenie. Kraków, Wydawnictwo Naukowe UP.

Sojda, S. (2016). Dynamika rozwoju współczesnego języka słowackiego - aspekt gramatyczny. Poznańskie Spotkania Jezzkoznawcze, 32, 157-167.

Toffler, A. (1985). Trzecia fala. Warszawa, PIW.

Waszakowa, K. (2017). Kognitywno-komunikacyjne aspekty słowotwórstwa. Wybrane zagadnienia opisu derywacji w języku polskim. Warszawa, Zakład Graficzny Uniwersytetu Warszawskiego.

Wilkoń, A. (2000). Typologia odmian językowych współczesnej polszczyzny. Katowice, Wydawnictwo Uniwersytetu Śląskiego.

Wolny, R. (2013). Prosumpcja i prosument na rynku e-usług, Konsumpcja i Rozwój, 1, 152-163.

Żmigrodzki A. (Ed.), Wielki słownik języka polskiego. Retrieved from: https://wsjp.pl/. 
Żydek-Bednarczuk, U. (2013). Dyskurs medialny. In E. Malinowska, J.Nocoń, U. Żydek-Bednarczuk (Eds), Style współczesnej polszczyzny. Przewodnik po stylistyce polskiej (pp. 179-197). Kraków, Universitas Publ.

Статья поступила в редакцию 21 августа 2020 г.; рекомендована в печать 23 октября 2020 г.

Контактная информация:

Шкудлярек-Щмехович Эва - д-р филол. наук, проф.; ewa.smiechowicz@uni.lodz.pl

\section{Syntactic innovations in Polish Internet communication}

\section{E. Szkudlarek-Śmiechowicz}

University of Lodz, 171/173, Pomorska str., Lodz, 90-236, Poland

For citation: Szkudlarek-Śmiechowicz, E. (2021). Syntactic innovations in Polish Internet communication. Media Linguistics, 8 (1), 57-70. https://doi.org/10.21638/spbu22.2021.105 (In Russian)

Today, the use of language on the Internet is the most important environment for the emergence of new language customs and variant forms. The article presents search results and the quantitative and qualitative analysis of two syntactic constructions: $\mathrm{X}$ and their non-normative variants: Y. The study takes into account the numerical ratio of normative and nonnormative constructions, comparative data from various types of discourses and media texts, including those derived from Polish Internet speech in its interactive and non-interactive variants, and a comparison of data from various periods (until 2000, 2001-2010, after 2010), when the Polish language did not succumb to the influence of network communication (or its impact was less). The sources of data are the National Corpus of Polish, Monco PL online news search engine and Forumowisko PL online forums. The overarching aim of the research is the initial implementation of research postulates formulated both in normative linguistics (developing research tools that will allow for the codification of the standard norm of Polish to be re-codified) and in the field of media linguistics (developing criteria for assessing the rules of communication in the network that will take into account the normative aspect of language in combination with the rules governing Internet communication).

Keywords: Internet communication, language norm, language dynamics, syntactic innovations, syntactic variability.

Author's information:

Ewa Szkudlarek-Śmiechowicz — Dr. Sci in Philology, Professor; ewa.smiechowicz@uni.lodz.pl 